\title{
Education and Nutritional Self-Care for Basic Level School Communities in Cuauhtemoc, Chihuahua, Mexico
}

\author{
Patricia Islas Salinas ${ }^{1 *}$, Claudia Teresa Domínguez Chavira ${ }^{2}$ and Alejandra González Chávez ${ }^{3}$ \\ ${ }^{1}$ Doctor en Educación, Mexico \\ ${ }^{2}$ Doctor en Ciencias de la Educación, Mexico \\ ${ }^{3}$ Maestra en Enfermería, Mexico \\ *Corresponding author: Patricia Islas Salinas, Universidad Autónoma de Ciudad Juárez, Cuauhtémoc, Chihuahua, México, Km 3.5 Carretera \\ Cuauhtémoc-Anáhuac, Cuauhtémoc Chih Mex
}

Submission: 制 October 09, 2017; Published: 眥 November 09, 2017

\begin{abstract}
The present study aims to foster a culture of self-care from Dorotea Orem nursing perspective, as well as to take nutritional health education and awareness about the benefits of the "healthy lunchbox" to beneficiaries and advisors for the program "Ampliando el Desarrollo de losNiños" (ADN) of the "Fundación del Empresario Chihuahuense" (FECHAC). Derived from the proposal to the ongoing reform of the Mexican educational system to promote an improvement in the nutritional quality of the students of basic education. The methodology has a mixed approach, which is intended to have an impact in the context and the collective schools through educational intervention. Where intervening means to introduce new elements in an already organized system; through human resources, materials or intellectuals who are not part of the grand educational context to help analyze the reality and promote social transformation that would benefit the participants. The results show a decreased perception of self-care in the population studied; on the other hand, there is a discrepancy between the perception and practice of good eating habits both at home and in school.
\end{abstract}

Keywords: Self-care; Nutrition; Eating habits; Educational intervention; Health education

Abbreviations: AND: Apliando el Desarrollo de los Niños (Expending Child Development); FECHAC: Fundación del Empresario Chihuahuense (Chihuahuense Enterprise Foundation); WHO: World Health Organization

\section{Introduction}

School age is a favorable stage to determine the habits and behaviors that will prevail for the rest of life; this is why health education is the approach to combat the problem of obesity and malnutrition, as well as to prevent diseases. The increase in the intake of fast food and sausages (inlaying)with high levels of sodium and conservatives have led modern and consumerist societies into chaos in the health area, the considerable increase in individuals with high blood pressure and diabetic problems, who are products of obesity or malnutrition, is today one of the problems of global health.

Although, health education has a preventive and corrective function that requires knowledge by the individual, the family and other social groups for the prevention of certain diseases, its main purpose is not to avoid the disease, but to promote healthy lifestyles; it has a positive sense of support and calls for a process of comprehensive health management [1]. Schools and home are the main areas where children develop physically and mentally, is through socialization that acquired learning, behaviors, and personal and community values will affect the quality of life of the individual in the later childhood stages; this can be achieved through health education, which is defined as a process of lifelong learning that begins in early childhood, oriented towards the knowledge of itself in all its dimensions as individual and social, and also of the surrounding environment in its double ecological and social dimension in order to be able to have a healthy life and participate in the collective health [1]. According to the Global Strategy for the health of women, children and adolescents, aspire to the realization of their rights to reach the highest possible level of health and well-being [2], and the declaration of children's rights in the eighth chapter, article 28 the right for health to combat malnutrition through the promotion of adequate feeding of the law for the protection of the rights of the children and adolescents [3], the project focuses on support to the different actors involved in the fulfillment of this right.

The World Health Organization (WHO) [2] defines health as the state of complete physical, mental and social well-being, and not 
only the absence of disease. This concept leads to the consideration on how the impact of the educational process should influence the global or holistic point of view from the people. In this sense , education incorporates the social factor as the element that also makes up the wellbeing of the people, it is a characteristic phenomenon and therefore society, becoming a decisive factor of the quality of life and well-being that happens to depend, not only in the world of health care, but also of the social world.

Therefore, in the right of Mexican boys and girls, it is priority to address the issues of health, especially in the aspect of self-care and nutrition education. However, currently families tend to use refined flour, bottled sodas, and fried foods or breaded, sugar and processed foods by being a faster, simpler and inexpensive way of providing the family meal [4].

\section{Description and Adaptation of the Model of Dorothea Orem for the Nutritional Self-Care of the Child}

In the health area, there are different theories and philosophies in nursing that focus on different health situations in order to care for, educate and improve the quality of life. Dorothea Orem, in his "Self-Care Deficit Theory" presents a general model based on three theories related, where intends to maintain the vital functionality of the human being through self-care. Theories on relationship are: the theory of self-care (describes why and how people take care of themselves), self-care deficit theory (describes and explains when and how nurses can help people) and the theory of systems of nursing (actions of the nurse who should be kept in the person confronted with problems of self-care or dependent care, through his professional practice as educational support) [5].

Dorothea Orem, in her theory, defined self-care as the activities people undertake according to their experience, in order to maintain the health, well-being and prolongs the personal development; at the same time, the self-care deficit is expressed as the rupture between the demands of self-care and the activities that are not favorable to meet established demands [6]. Likewise, she defined nursing as a professional who is responsible for, with their skills, knowledge, and human service, to take care of the person who cannot do it by itself, either to maintain the health, life and wellbeing. This care can be directed individually or in group as a partial or total support, guidance, physical and psychological support, promote a healthy environment and finally teach the person to selfcare [7].

Based on the above mentioned and taking elements of the "SelfCare Deficit Theory " of Dorothea Orem, the following scheme is performed as a reference of educational intervention so that children in the program "AND" of "FECHAC", can reflect, raise awareness in making self-care decisions in their nutritional health. The scheme above, show the impact for the educational intervention, showing that different factors (belonging to the children) may be involved on the activities and decisions that must be taken. For Orem (cited by Marriner) [6], a person is a dynamic and comprehensive being, this means he/she has the ability to use the ideas and thoughts to reflect and make the decision to carry out self-care actions for their own human development. This concept, related with the scheme above and coupled with that of health education, should meet the goal of health and care of children and their parents, by being able to influence their thinking and commitment in the search for the own well-being and family. As indicated at then in the health promotion conference, from the educational intervention people can choose healthy options to have greater control of their own health [8] (Figure 1).

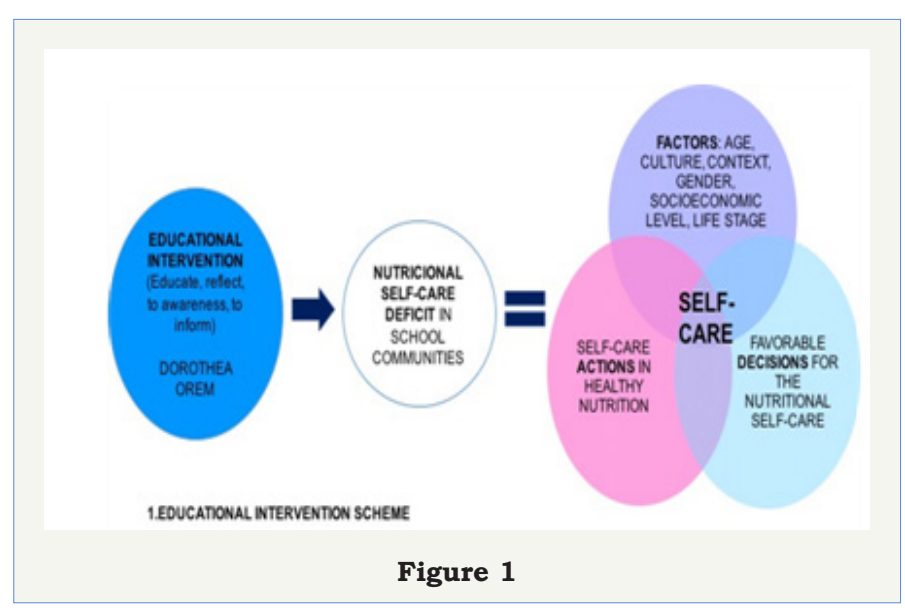

\section{Full Time School Model}

Full Time Schools (FTS) are public schools of basic education, extending the school day to expand the opportunities of children and adolescents knowledge. Full Time School is designed as an educational strategy that aims to expand learning opportunities and strengthen the development of competences of students according to the purposes of basic education, taking advantage of the extension of the school day [9]. In Mexico Full Time School mode initiated in 2007, a FTS is one that expands its working hours from 6 to 8 hours a day, to strengthen the quality of learning; optimize the effective use of school time with the aim of reinforcing the reading, mathematics, art competitions and culture, recreation and physical development and, finally, strengthens the processes of inclusion and co-existence in school. These schools operate on preschool, elementary and middle school.

Basic education schools, do not have human resources, did act materials and infrastructure to support the Full Time Model. Teachers demand support from civil society and municipal authorities to implement the Full Time Model to support the feeding needs of students especially those who come from marginal colonies, this have seen the need for those children whose parents have no money or time to provide them with adequate food.

\section{FECHAC Model}

The "Fundación del Empresario Chihuahuense" (FECHAC), is a non-profit, independent and nonpartisan organization, which finances social projects of organizations of civil society and community groups, to promote human and social development of Chihuahua. FECHAC is a mean that more than 31,000 Chihuahua businessmen use to bring their support to the community. It is 
an independent and autonomous organization nonpartisan and nonprofit, dedicated to the critical needs of the community in the field of basic education, preventive health and social capital formation, with the purpose of raising the quality of life of the Chihuahua, promoting corporate social responsibility, citizen participation and the strengthening of civil society organizations, in the arduous effort to continue building and strengthening our community.

Model FECHAC ADN (Ampliando el Desarrollo de losNiños), is designed to be taught in schools of basic education (preschool, elementary and middle school). This model operates during the school year and implements a program of extra school activities with the aim to develop learning skills and physical abilities in children and adolescents, strengthens self-esteem and selfknowledge, which has a palpable and immediate impact on its development and growth.

The ADN project in Cuauhtemoc, offers a new perspective for the integral development of 930 children and adolescents of basic level education, this school model allows hundreds of children to pass their afternoons productively and supervised, while their parents work. One of its goals is the nutritional support of children who belong to group of selected schools whose characteristic is a low socio-economic level, where there is a situation of bad nutrition among the members of the families [10].

\section{Contextual Approach}

Cuauhtémoc city is located in the central-west region of Chihuahua State, Mexico, in the foothills of the Sierra Madre Occidental. Its population is 134,785 inhabitants that is the third city with the largest population in the state. Cuauhtémoc presents a range of average age between 21 and 25 years [11], here the majority of parents are located in an economically productive age, this is the reason why many of them are out of home and unable to prepare home cooked meals for their children or their resources are low; the bulk of the population is engaged in economic activities as employees of various companies, as well as fruit and agricultural laborers since Cuauhtemoc is a region mainly producing and maintaining apple.

The average level of schooling population is of 15 years and over in the city, is equivalent to the second middle school grade, this in turn reflect salaries that are low and not sufficient for the needs of an average family. In 2010, the city had 77 preschools (3.2\% of the state total), 80 elementary schools $(2.8 \%$ of the total) and 27 middle schools (3.6\%) [12]. These schools cover a schedule of 3.5 hours class in preschool, 4.5 in elementary schools and 6 hours class in middle school. Although in Mexico there is an extended time program created by the Federation, there is no record whether Cuauhtemoc has this program in different schools of basic education, that is, the three levels of education: preschool, elementary and middle school.

\section{Methodology}

Social intervention is intended to improve the context and the group of schools, the objectives that are handled in this type of research are formal and organized actions that solve a problem, try to respond to social needs, significantly influencing the interaction of people to aspire to a public or social legitimacy [13].

This project deals with the social and educational intervention as a phenomenon that must be attended from a mixed research design, where the qualitative part is phenomenological, because that describes and analyzes the daily reality of the participants, the quantitative part is based on the measuring of the habits of selfcare and food preferences of the participants through three phases:

1. Implementation of a first instrument.

2. Development of a workshop designed specifically for each participating group to address nutrition care and self-care issues, with didactic support and technology use.

\section{Application of post instrument}

\section{Participants}

School population incorporated into program ADN FECHAC of 525 children in an age range of 4 to 16 years, 200 parents, as well as 30 promoters and cooks of the program, of 9 schools of basic education in its three educational levels ( 2 preschools, 5 elementary and 2 middle schools).

\section{Instruments and Data Collection}

Data collection was based on three instruments:

1. Closed survey aimed at students: is composed of 9 questions about nutrition and 7 of self-care.

2. Open survey for parents: Parents instrument consists of 14 questions concerning about food and nutrition, having as base the Global School based Student Health Survey from World Health Organization (WHO), as well as 4 questions about perception of self-care.

3. Diagnostic questionnaire for the promoters and cooks: consists of 14 questions about food handling.

\section{Results}

\section{Quantitative part results}

First phase: A descriptive study is made with the purpose of identifying the habits and customs of the students about their nutrition within the time of stay in the school, before the pedagogical intervention of the workshop. For the analysis of the data, food information is grouped into two types: healthy foods and beverages (fruit, vegetables, sandwiches and burritos, natural water and homemade fruit water) and junk foods (potato chips, packaged cookies; soft drinks, sugary drinks and commercial juices). The results are shown below:

A. The tendency of students in the consumption of junk foods (food and beverages) prior to the pedagogical intervention is $61.1 \%$. Against $38.9 \%$ in the preference for healthy foods (Figure 2). 


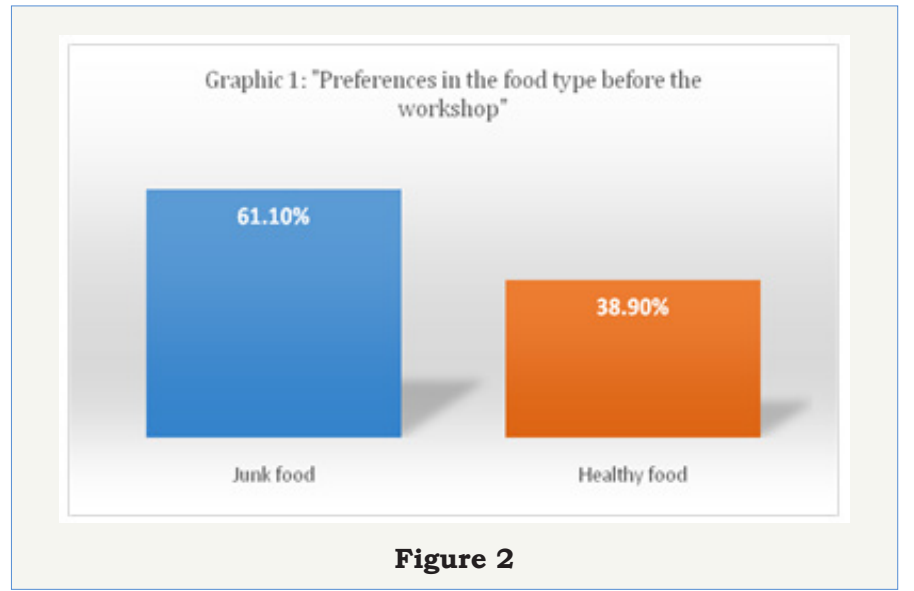

B. $61.2 \%$ of the students consume junk foods during the lunch break, specifically chips and cookies.

C. Only $8.9 \%$ of the students tend to consume fruits and vegetables during their stay at school. While $29.9 \%$ consume traditional foods prepared at home like burritos and sandwich.

D. Contrastingly, $57.25 \%$ usually drink natural water, $7 \%$ drink fruit water, while $35.75 \%$ drink soft drinks, juices and sugary drinks (should be noted that the population studied belongs to a community whose socioeconomic level is low and the cost of these drinks is expensive).

Second stage: A comparative study is made in relation to the results of the pre-test and post-test of the survey directed to the students. For the analysis of the data, food information is grouped into two types: healthy foods and beverages (fruit, vegetables, sandwiches and burritos, natural water and homemade fruit water) and junk foods (potato chips, packaged cookies; soft drinks, sugary drinks and commercial juices). Subsequently, a descriptive statistics analysis is carried out through the Excel program; with which is obtained the database, whose results are shown below:

A. Once the workshop is implemented, the students show a decrease in their preferences and habits of junk food consumption by $2 \%$; while the increase in the consumption of healthy foods increases proportionally (Figure 3).

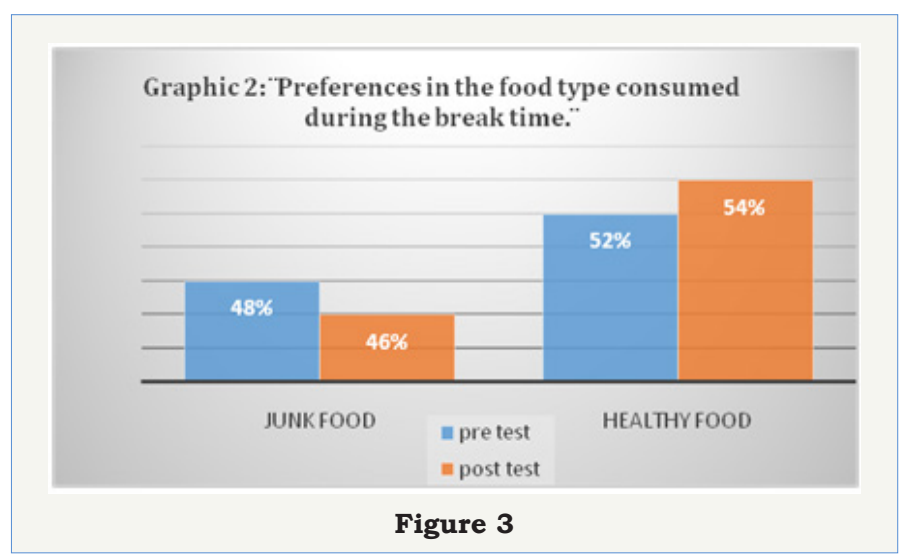

B. The student population analyzed reports that at home the daily food intake of the group of fruits and vegetables corresponded to $11.2 \%$ at first. On the other hand, the information in the post test shows that the students increased to $17 \%$ in the amount consumed at home. So it is inferred that the workshop impacted parents about the awareness in the use of this group of foods. Similarly, the consumption of traditional foods prepared at home such as burritos and sandwiches increased from $35.6 \%$ to $43.5 \%$ after the workshop.

\section{Third phase:}

A. Self-care: In what refers to self-care, preliminary analysis indicates that the majority of children does not have clear the concept of self-care, is not related to body image or well-being, even though the basic rules of hygiene are present and are important for most. They are aware that eating healthy foods is good for their health, however, $60 \%$ of students indicate that they eat foods that they like although they are unhealthy, only $3 \%$ understand that healthy foods can also be delicious, $26 \%$ relate the care of the body with the intake of foods that taste good, $5 \%$ acknowledge that the food they eat is unhealthy and $6 \%$ indicate that you know you must eat healthy foods to care for your body, so it follows that do not receive positive reinforcement at home or at school.

\section{Qualitative part results}

For the analysis of the data of the interviews conducted to the parents and cooks, the Atlas Ti version 6.0 program was used, with which categories were obtained, the most significant being shown below:

A. Parents: B. Ignorance of food groups: In the application of the pretest, parents were confused with the concepts of the food groups on the eat-well plate as well as they should be combined. There is a lack of knowledge about the nutrients contained in the different groups.

B. Good disposition to learn: They were positive and showed interest in learning how to support their family with the combination of food and to prepare healthy lunch box for their children.

C. Usefulness of what has been learned in everyday life: In the implementation phase of the post test, mentioned that it was useful graphic support on topics (a magnet to stick on the fridge) and also the healthy lunch box menu since this facilitated purchases for the super market and on the preparation of the daily food.

\section{Cooks:}

A. Poor knowledge about food groups in the eat-well plate: The cooks show poor knowledge in the eat-well plate; some indicate that they have no previous studies about food groups and their nutritional content. In the same way they did not know the combinations and quantities suitable for feeding the children. Most cooks base the preparation of the food on the experience in their own home.

B. Scarce knowledge about food safety standards: The cooks showed poor knowledge on the bio-security laws necessary to prevent pollution; they indicate that they did not receive training 
about this. Cooks apply the hygiene standards they use in their own homes; however they do not take into account that the amount of food prepared in the school is in large portions and exist a greater risk of contamination.

C. Good willingness to learn: During the workshop the cooks showed a good attitude and desire to know the different bio-safety regulations. The cooks gladly accepted the tips provided by the workshops, such as the placement of the eat-well plate and biosecurity rules on the wall of their kitchens. With respect to personal hygiene and safety standards such as the use of a cap and gloves, they showed interest in using them.

D. Application of the knowledge learned: In a subsequent visit of the workshop it was observed that the diagrams provided by FECHAC were placed on the walls of the kitchens. They also decided to change the distribution of food in their pantry and in the refrigerator, according to the suggestions of the workshop, also they use the scheme of colors for the use of knives and cutting boards and thus avoid cross contamination.

\section{Conclusion}

The action hypothesis of the research and educational intervention was that participants of the project improve their lifestyle, eating habits, knowledge of the importance of healthy lunchbox and the perception of self-care through the education guidance and health care provided during the implementation of the workshop, so the actors can carry them to their families for the prevention of diseases. The present study highlights the satisfaction and opening of the participants with the healthy eating and lunchbox workshops, as well as the aspect of self-care, who participated and responded in an open interested way of learning of new concepts and reinforcing others.

The importance of integrating parents and children as a family in the formation and strengthening of a healthier life is demonstrate. This constitute a challenge but is possible to make changes in the eating habits of the families of school children and who are also in low socioeconomic level, with the design and implementation of an innovative educational model that includes participatory activities and the use of technology tools. Despite the fact that children receive information about hygiene and healthy habits through the "Secretaria de Education Publica" (SEP) programs, this information is usually only aimed at school children and not their families and is not continuous or strong to achieve a change in habits and lifestyle in the major contexts where the child is educated as are the home and school.
At the end of the workshop, it is concluded that students fail to conceptualize the characteristics of a junk food even if they distinguish the concept of healthy food and water as the main healthy drink. It is inferred that this may be a consequence of the impact of marketing on the minds of children or consumption at home.

The results show the need to promote education nutritional health and self-care among students from nine schools in which the project is carried out. It is for this reason the design of a course subject for the ADN model is proposed, based on a manual of nutritional education and self-care that can be used by moderators and coordinators of the program to provide health education and self-care to the beneficiaries.

\section{References}

1. Quesad R (2004) Educación para la salud: (reto de nuestro tiempo). Ediciones Díaz de Santos. Madrid Españaz. p. 43.

2. WHO (2015) Estrategia Mundial para la Salud de la Mujer, el Niño y el Adolescente (2016-2030). Sobrevivir, prosperar, transformar. .

3. UNICEF (1989) Ley para la protección de los derechos de niñas, niños y adolescentes.

4. González U, Mazorra R, Horta H (2002) Factores sociales predisponentes de la obesidad. Revista digital buenos Aires. 8(48):

5. Navarro Y, Castro M (2010) Modelo de Dorothea Orem aplicado a un grupo comunitario a través del proceso de enfermería. Enfermería Global 9(2):

6. Marriner A, Raile M (2002) Modelos y teorías en enfermería. Harcourt Brace. Barcelona.

7. Prado L, González M, Paz N, Romero K (2014) La teoría Déficit de autocuidado: Dorothea Orem punto de partida para calidad en la atención. Revista Médica Electrónica 36(6): 835-845.

8. OMS (2016) 9. ${ }^{\text {a }}$ Conferencia Mundial de Promoción de la Salud: Shangai.

9. (2010) Secretaria de Educación Publica (SEP) Programa Escuelas de tiempo completo.

10. FECHAC (2016) Fundación del Empresariado Chihuahuense, AC formando comunidad.

11. (2017) Instituto Nacional de Estadística y Geografía. México en Cifras. Información nacional por entidad federativa y municipio.

12. (2010) Consejo Nacional de Evaluación de la Política de Desarrollo Social (CONEVAL). Informe anual sobre la situación de pobreza y rezago social. Cuauhtémoc, Chihuahua.

13. Fantova F (2007) Repensando la intervención social. Revista documentación social. pp. 183-198. 